\title{
O PENSAMENTO DE HAYEK E OS DESAFIOS DAS EMPRESAS BRASILEIRAS EM TEMPO DE CRISE ECONÔMICA CAUSADA PELA COVID-19
}

\section{Márcia Assumpção Lima Momm* Viviane Coêlho de Séllos Knoerr*}

\section{RESUMO}

$\mathrm{O}$ artigo tem como escopo analisar em que medida o pensamento liberal de Hayek se compatibiliza-se com os princípios da livre iniciativa e da liberdade econômica, que fundamentam o Estado Democrático brasileiro, e pode ser aplicado para o enfrentamento dos desafios das empresas brasileiras em tempos de crises sanitária e econômica causadas pelo novo coronavírus. $\mathrm{O}$ artigo traz como contribuição o debate do neoliberalismo no Brasil, o qual intensificou-se mediante a edição da Lei da Liberdade Econômica, evidenciando as concepções hayekianas da livre iniciativa.

Palavras-chave: Hayek; Livre iniciativa; Crise sanitária e econômica; Coronavírus.

\section{HAYEK'S THINKING AND THE CHALLENGES OF BRAZILIAN COMPANIES IN TIME OF ECONOMIC CRISIS CAUSED BY COVID-19}

\begin{abstract}
The article aims to analyze the extent to which Hayek's liberal thinking is compatible with the principles of free initiative and economic freedom, which underlie the Brazilian Democratic State, and can be applied to face the challenges of Brazilian companies in times health and economic crises caused by the new coronavirus. The article brings as a contribution the debate of neoliberalism in Brazil, which was intensified through the edition of the Law of Economic Freedom, evidencing the Hayekian conceptions of free initiative.
\end{abstract}

Keywords: Hayek; Free Initiative; Sanitary and economic crisis; Coronavirus.

\section{INTRODUÇÃO}

\footnotetext{
Mestranda em Direito Empresarial e Cidadania pelo Centro Universitário Curitiba - UniCuritiba. Pósgraduanda em Direitos Humanos e Direito Constitucional, do Direito do Trabalho e do Direito Previdenciário pelo Ius Gentium Conimbrigae, Coimbra, Portugal/PT. Advogada e especialista em Direito do Trabalho e Processo do Trabalho pela UNIVALI e em Gestão Estratégica de Planejamento Tributário pela UNESA. Orcid IiD: http://orcid.org/0000-0001-5841-4992. Lattes iD: http://lattes.cnpq.br/6435845130832671. E-mail: marciaassump@ hotmail.com.

Doutora em Direito do Estado pela Pontifícia Universidade Católica de São Paulo. Mestre em Direito das Relações Sociais pela Pontifícia Universidade Católica de São Paulo. Professora Orientadora e Coordenadora do Programa de Mestrado e Doutorado em Direito Empresarial e Cidadania do UniCuritiba. Orcid IiD: http://orcid.org/0000-0002-7762-7907. Lattes iD: http://lattes.cnpq.br/4609374374280294. E-mail: viviane@sellosknoerr.com.br.
} 
Os temas da livre iniciativa, da liberdade econômica e do capital voltaram ao âmago dos debates, na medida em que o Brasil precisa avançar e desenvolver-se economicamente, permitir que a iniciativa privada possa gerar e produzir riqueza, arrecadar tributos e, por fim, o Estado possa exercer a sua finalidade.

Ao agravar-se a crise econômica no País, em decorrência da pandemia causada pela covid-19, o Estado não deve ser agente limitador ao uso da propriedade privada, bem como, deve instituir mecanismos para que as pessoas possam empreender com liberdade.

Nesta direção, analisar-se-á as teorias de Friedrich August Von Hayek e os princípios fundamentais da livre iniciativa e da garantia ao livre exercício de atividade econômica, bem como, o papel do Estado neoliberal brasileiro para o desenvolvimento socioeconômico, a fim de promover o bem-estar e a justiça social.

Este artigo terá como objeto analisar em que medida o pensamento liberal de Hayek se compatibiliza-se com os princípios da livre iniciativa e da liberdade econômica, dispostos no inciso IV do caput do art. $1^{\circ}$, do parágrafo único do art. 170 e do caput do art. 174, da Constituição da República, e como pode ser aplicado para o enfrentamento dos desafios das empresas brasileiras em tempos de crises sanitária e econômica causadas pelo novo coronavírus.

Com o intuito de contribuir para esta análise, ainda que de forma breve, o presente trabalho abordará, num primeiro momento, o Estado de Direito e o Estado neoliberal brasileiro, os efeitos socioeconômicos e as fórmulas desenvolvimentistas e o seu surgimento no país, pontuando os seus vieses político e econômico. Na sequência, tratar-se-á dos princípios da livre iniciativa e da liberdade econômica, que fundamentam a ordem econômica e o sistema capitalista, pautado na livre concorrência e no livre exercício de qualquer atividade econômica. Finalmente, buscar-se-á analisar estes preceitos normativos à luz do pensamento de Hayek, objetivando responder a indagação se viabilizam-se a autonomia do particular para empreender em período de crise.

O método de abordagem a utilizar-se é o dedutivo e nas diversas fases da pesquisa serão acionadas as técnicas da pesquisa bibliográfica e documental (legislativa e jurisprudencial), mediante a análise da fundamentação das decisões nas Ações Direta de Inconstitucionalidade quanto à legitimidade das medidas trabalhistas para o enfrentamento do estado de calamidade pública para a manutenção dos empregos e da atividade empresarial. 


\section{O ESTADO DEMOCRÁTICO DE DIREITO EM UMA ORDEM NEOLIBERAL NO} BRASIL

Neste capítulo tratar-se-á sobre a concepção do Estado de Direito, sob a visão ultraliberal do economista e filósofo austríaco Friedrich August von Hayek (1899-1992). Este autor foi um dos maiores representantes da Escola Austríaca de pensamento econômico, com suas ideias teórico-ideológicas do neoliberalismo.

No pensamento de Hayek (2006), o liberalismo não é um axioma, mas um conjunto de princípios capazes de inspirar ações no sentido de mudança social. Entre esses princípios está o direito à liberdade, definido como o fundamento do Estado de Direito que deve garantir, fundamentalmente, a primazia da liberdade econômica sobre as exigências legais e administrativas discriminatórias, ou seja, regulamentação e interferência estatais mínimas; o reconhecimento da propriedade privada como condição para a liberdade econômica e política; e, fundamentalmente, a supremacia do mercado para dirimir as diferenças sociais.

Examinar-se-á, ainda, a evolução do Estado neoliberal brasileiro inspirada na visão deste grande pensador econômico do século XX.

\subsection{Estado de Direito na concepção de Hayek}

A observância do princípio do Estado de Direito, para Hayek, é uma característica clara que "distingue um país livre de um país submetido a um governo arbitrário" (2020a, p. 157), significando que todas as ações do governo são regidas por regras pré-estabelecidas e amplamente divulgadas.

Hayek "defende a constituição de um Direito e uma Ordem que possibilite os princípios liberais, critica a noção de Justiça Social e a democracia nos moldes do Estado Social” (PAZ, 2019, p. 13). Sua argumentação é pautada nos princípios liberais da separação dos Poderes, respeito à dignidade humana, da igualdade perante a lei e do império da lei.

Na obra intitulada O caminho da servidão (HAYEK, 2020a), publicada originalmente em 1944, o autor opõe-se à planificação da economia, típico dos regimes totalitários, em face dessa criar brecha para a concentração de poderes nas mãos dos governantes, refletindo nas estruturas de poder que, em nome de um projeto coletivo, interfere 
na vida privada dos indivíduos, esmagando as liberdades e garantias individuais e substituindo uma ordem espontânea e livre por uma enrijecida e autoritária (ONOFRE, 2014).

O Estado de Direito não deve interferir na liberdade; este deve permitir que os indivíduos possam traçar os seus próprios planos. Deste modo, na teoria de Hayek (2020a, p. 161):

\begin{abstract}
O Estado deve limitar-se a estabelecer normas aplicáveis a situações gerais deixando os indivíduos livres em tudo que depende das circunstâncias de tempo e lugar, porque só os indivíduos poderão conhecer plenamente as circunstâncias relativas a cada caso e a elas adaptar suas ações. Para que o indivíduo possa empregar com eficácia seus conhecimentos na elaboração de planos, deve estar em condições de prever as ações do Estado que possam afetar esses planos.
\end{abstract}

Em outras palavras, o indivíduo como consumidor ou como empresário é livre, a ação humana de cada um determina a sua situação de vida. A individualidade é o pressuposto irredutível da ação humana na economia (MISES, 2017).

No pensamento de Hayek, o Estado não deve assumir um papel de racionalização das relações sociais e econômicas, e questões como propriedade privada, contrato, honestidade e outros valores morais, as quais funcionam e permitem à livre sociedade agir. O Estado deve proteger e garantir a continuidade da ordem liberal, não devendo avocar uma postura intervencionista do livre mercado (PAZ, 2019).

Hayek defende os valores da liberdade individual, em detrimento da intervenção do Estado e contra as ameaças do socialismo, como mecanismo eficaz de fomento ao progresso social. "Em uma sociedade livre o Estado não administra os negócios dos cidadãos; administra justiça a indivíduos que permanecem proprietários e diretores de suas próprias tarefas" (HAYEK, 2006, p. 256).

Segundo Onofre (2014, p. 197), a luta de Hayek "contra a intervenção estatal nos assuntos econômicos foi baseada no entendimento de que a ação de qualquer governo é mais ineficiente do que a liberdade das ações individuais para o desenvolvimento econômico".

Nesta percepção, o Estado de Direito, para Hayek, compreendendo um Governo que observa a Constituição e as leis, sendo estas fundadas em certos princípios, garante a liberdade dos indivíduos e alicerça a ordem liberal, permitindo a construção e a preservação de uma sociedade livre (PAZ, 2014). 
Em seu livro intitulado Los fundamentos de la libertad (2006), citando o pensamento de Adam Smith, Hayek elucida que o esforço natural de cada indivíduo para melhorar a sua própria condição, quando exercitado de forma livre e segura, constitui um princípio tão poderoso que por si só e sem qualquer assistência não é apenas capaz de levar à prosperidade e à riqueza da sociedade, mas para superar obstruções impertinentes com as quais a loucura das leis humanas muitas vezes impede o seu funcionamento.

O pensamento de Hayek é o anseio de todo o indivíduo e de toda a sociedade livre: liberdade, principalmente individual, prosperidade e paz social, que somente podem ser alcançados mediante um Estado mais liberal, com menor ingerência na economia, não interferindo em preços, salários, moeda e juros, entre outros, adotando uma economia de mercado (HAYEK, 2011).

Outra avaliação de Hayek quanto à preservação da liberdade individual são os efeitos danosos das ações do governo sobre as finanças e os gastos públicos (2011, p. 135):

\footnotetext{
Se queremos preservar uma economia de mercado que funcione (e com ela a liberdade individual), não há nada mais urgente do que dissolver o casamento ilegítimo entre as políticas fiscais e monetárias, casamento este que, se foi clandestino durante muito tempo, acabou sendo consagrado com a vitória da economia "keynesiana". (grifos do autor)
}

A liberdade econômica é o centro deste ensaio e o pensamento liberal de Hayek de um Estado mínimo e de proteção às liberdades individuais, para trabalhar em que se convém ou fazer acordos comerciais; são subsídios para o desenvolvimento social e humano e o alcance do bem-estar comum (CUNHA, 2011).

Sem embargo, cabe destacar que a concepção liberal de Hayek, para alguns é um pouco apologética; no entanto, atua no sentido de permitir que os indivíduos possam empreender com liberdade e em um ambiente de livre concorrência, nos princípios contidos em nossa Carta Constitucional relevantes para o desenvolvimento econômico, visando a atingir a justiça social e a dignidade humana.

\subsection{Estado democrático brasileiro: transição}

A partir do final da década de 70 e início dos anos 80, o Estado brasileiro passa por transformações econômicas, marcadas pela transição do capitalismo mundial para a sua forma 
transnacional, pela emergência de movimentos e formas de organização dos segmentos sociais e pela modificação do Estado, a fim de que este ajustasse-se à lógica econômica internacional hegemônica.

Na concepção de Dardot e Laval (2016, p. 14), neste período "o neoliberalismo foi interpretado em geral como se fosse ao mesmo tempo uma ideologia e uma política econômica diretamente inspirada nessa ideologia”.

A redemocratização política pátria, ocorrida em 1985, impulsionada primordialmente pelo agravamento da crise econômica, crescimento da dívida externa, da inflação e da recessão no Brasil nos anos finais da Ditadura Militar, leva-se a discussão de fórmulas para o enfrentamento destas crises, mediante a adoção dentre elas de políticas neoliberais, com o intuito de solucionar as fraturas nas articulações entre o Estado e suas empresas, os capitais privados locais e o capital internacional, bem como, entre o setor público e o privado.

Inspirando-se em modelos estrangeiros, como o de Margaret Thatcher, no Reino Unido, e de Ronald Reagan, nos Estados Unidos da América, estes influenciados, majoritariamente, pelas doutrinas liberais de Hayek, que desde a década de 1940 defendia uma diminuição da ação do Estado na economia, com suas ideias de desregulamentação, privatização e política de livre mercado mediante a intervenção mínima do Estado, o paradigma nacional desabrocha lentamente a partir da Constituição da República de 1988, na qual se introduz no Brasil um Estado Democrático de Direito pautado na livre iniciativa, na liberdade econômica e no valor social do trabalho, com o objetivo de promover o bem de todos e o desenvolvimento nacional.

Dessarte, a concepção liberal da economia aparece sob o desígnio do neoliberalismo, um Estado, nem liberal, nem social, mas um Estado Democrático subsidiário, obrigado a regular as relações econômicas com o intuito de evitar o colapso do sistema capitalista ou, ao menos, de significativas crises causadas por este sistema.

Sobre este novo pensamento de Estado e o seu papel no desenvolvimento da sociedade, discorre Di Pietro (2017, p. 18):

No âmbito interno, o princípio da subsidiariedade está na própria base da nova concepção do Estado de Direito Social e Democrático, ou seja, de um Estado em que os direitos fundamentais do homem já não constituem apenas uma barreira à atuação do Estado, como se via no período liberal, mas constituem a própria razão de ser do Estado. Cabe a este promover, estimular, criar condições para que o indivíduo se desenvolva livremente e igualmente dentro de uma sociedade; para isso é necessário 
que se criem condições para a participação do cidadão no processo político e no controle das atividades governamentais.

Mello (2019), jurista crítico do movimento liberal, divaga sobre o fim da dualidade política, militar, econômica e ideológica, do socialismo e o capitalismo, após a queda do muro de Berlim no final da década de 80, e a progressão do capitalismo, com a abertura econômica e a globalização, trazendo de novo à baila as teses do livre mercado e do Estado mínimo, cumprindo este, apenas, o papel de regular as atividades privadas, deixando de ter presença ativa no meio socioeconômico, privatizando as estatais.

Transitando do Estado liberal, sem ter sido implementado no país o Estado social, surge então a ideia, importada do liberalismo hayekiano, que demanda a eliminação de limites aos mercados e defende a livre iniciativa, a livre concorrência e a intervenção mínima do Estado na economia. Esta nova roupagem tem por pressuposto desonerar o Estado de funções sociais e postular a liberdade essencialmente em relação ao comércio e à circulação de capital, no que se diferencia do liberalismo clássico, que cultuava a supremacia do valor "liberdade" a toda e qualquer manifestação da vida humana (BASTOS, 2000).

Nos anos 90, com a eleição de Fernando Collor de Mello (PRN), o mandato-tampão de Itamar Franco (PMDB), e, principalmente, no governo de Fernando Henrique Cardoso (PSDB), as políticas e medidas neoliberais vão se mostrando relevantes para a retomada do crescimento econômico e redução das tensões sociais, efetivando-se mediante a estabilidade econômica e a diminuição paulatina da intervenção do Estado no sistema produtivo.

Assim, para se amoldar-se à nova racionalidade neoliberal, em ascensão e dar suporte ao reflexo da globalização no mundo jurídico brasileiro, a Constituição da República de 1988, fundamentada na livre iniciativa e na liberdade econômica, sofre modificações por várias emendas constitucionais, com objetivo de diminuir o papel do Estado na economia, dando abertura para as privatizações, para as parcerias público-privadas e novos institutos jurídicos, como os contratos de gestão e as agências reguladoras, entre outros.

A doutrina política e econômica do Brasil, baseada no neoliberalismo, assentou-se primordialmente na abertura comercial e financeira da economia, no investimento estrangeiro direto, na austeridade fiscal, nas privatizações de serviços públicos, na desregulamentação da economia - com a flexibilização de leis econômicas e trabalhistas - etc. Isto é, de modo geral e sucinto, o neoliberalismo balizou-se em duas frentes: a redução do tamanho do Estado e, por consequência, a expansão do papel do mercado e do setor privado para a economia. 
Estas medidas neoliberais originam-se da cartilha do economista John Williamson, um dos responsáveis pelo delineamento das propostas aprovadas no "Consenso de Washington" em 1989, tendo considerado que este deveria ser entendido, pela América Latina, tal como um "receituário" a ser cumprido pelos Estados que desejassem ajustar-se às novas circunstâncias. Seu conjunto de propostas previa, dentre outras (LEME, 2010): i) o equilíbrio das contas públicas, obtidas a partir das reduções de despesas e não pelo aumento de impostos; ii) a abertura comercial e um processo de desregulamentação com redução do controle governamental sobre o setor privado; e iii) um processo amplo de privatização como solução mais eficaz para transferir para o setor privado as empresas do Estado que, por sua vez, passariam a atuar sobre as leis do mercado, fortalecendo o ambiente competitivo.

Medidas que permitiriam, a um só tempo, a resolução do problema fiscal do Estado e, de outro lado, a indução de um progresso técnico que somente os capitais privados transnacionais poderiam ofertar, na forma de produtos e serviços.

Para o Brasil, em particular, as estratégias recomendadas foram as de que houvesse, ainda, as reformas constitucionais - sobretudo na área fiscal - para a redução dos impostos sobre os capitais privados; a desregulamentação dos aspectos econômicos em todas as instâncias; a flexibilização dos direitos trabalhistas; e as reformas no aparato burocrático do Estado, a fim de reduzir gastos em geral, incluindo aquelas em recursos humanos (SAUER, 2002).

Conduzindo-se por esta cartilha, nos anos 90 o Brasil teve o seu auge de serviços públicos privatizados ou desestatizados, por meio de autorizações, concessões e permissões administrativas decorrentes do Plano Nacional de Desestatização (PND), instituído pela Lei $n^{\circ}$ 8.031, de 1990. A primeira tentativa de privatização das empresas estatais, fora em busca de reduzir a dívida pública e retomada de investimentos às empresas transferidas à esfera privada, assim como para a introdução do capital estrangeiro no país.

A partir de então, várias emendas constitucionais permitiram a delegação da prestação de serviços públicos de competência do Estado para a iniciativa privada.

Outras alterações ao Estado desenvolvimentista restaram evidenciadas no mandato do sociólogo Fernando Henrique Cardoso, mediante a privatização de várias estatais, como a Embratel, a Embraer, a Vale do Rio Doce e a Companhia Siderúrgica Nacional. Houve também ampla abertura do mercado nacional para empresas estrangeiras. 
Naquele contexto, surgiu a necessidade de se instituir-se órgãos fiscalizadores e reguladores das atividades privatizadas, que antes eram de responsabilidade do Estado e passaram a ser da iniciativa privada, pois, uma vez nas mãos de pessoas privadas, haveria o risco de abuso de poder econômico e desvio de finalidade.

A livre iniciativa e a liberdade de exercício de atividade econômica passam a preconizar esta nova concepção de Estado, contextualizada na Constituição brasileira de 1988, porém o ordenamento jurídico pátrio dá uma tutela jurisdicional que, além de buscar a livre concorrência, a liberdade econômica, deve visar à dignidade, ao bem-estar e à justiça social.

Visto isto, a liberdade deve ser analisada no seu aspecto amplo, como um meio para atingir à coletividade e não como fim em si próprio. Urge, dessarte, a necessidade de subsídios do Estado regulador para que se possa chegar a uma efetivação real de liberdade econômica com dignidade e desenvolvimento social e não apenas um mero crescimento econômico que olvida as necessidades básicas dos indivíduos.

Sobre o tema, Di Pietro (2017, p. 16) preleciona:

\begin{abstract}
Com a nova concepção do Estado de Direito, o interesse público humaniza-se, à medida que passa a preocupar-se não só com os bens materiais que a liberdade de iniciativa almeja, mas também com valores considerados essenciais à existência digna; quer-se liberdade com dignidade, o que exige atuação do Estado para diminuir as desigualdades sociais e levar a toda a coletividade o bem-estar social. $\mathrm{O}$ interesse público, considerado sob o aspecto jurídico, reveste-se de um aspecto ideológico e passa a confundir-se com a ideia de bem comum.
\end{abstract}

Naquela concepção, já desenvolvida no fim do século XIX e início do século XX, o Estado deve abster-se de exercer algumas atividades, deixando-as nas mãos da iniciativa privada, com os seus próprios recursos, para desempenhar de forma mais eficaz e enérgica o que lhe compete: coordenar, fomentar e fiscalizar, permitindo aos particulares o sucesso na condução de seus empreendimentos, bem como, subsidiariamente, formar parcerias públicoprivadas. Nesta linha de prestígio à liberdade de iniciativa, o Estado só agiria quando a sociedade não conseguisse agir por si.

Nos 13 anos dos Governos Lula-Dilma (PT), no início deste século XXI, deu-se uma paralisada nesta racionalidade neoliberal, o Estado brasileiro volta-se para o assistencialismo; contudo, da esperança de crescimento econômico, ampliação de empregos e de programas sociais e redução da pobreza, o Brasil foi à crise, não só moral, por conta dos casos de corrupção, mas causada pela má administração, com as pedaladas fiscais e gasto excessivo 
com programas sociais, deixando o país com rombo nas contas públicas, recessão e retorno da inflação.

As ideias de um Estado neoliberal tiveram seu retorno ao país, somente em 2016, com o impeachment de Dilma Rousseff e a ascensão ao poder do seu vice, Michel Temer (PMDB), permanecendo no Governo atual, na qual buscam implementar uma agenda de reorganização estrutural do Estado para fins de desenvolvimento nacional, crescimento econômico e suporte à iniciativa privada para possibilitar gerar mais emprego e renda, adotando medidas de flexibilização trabalhista, por meio da Lei $n^{\circ}$ 13.467/2017 (Reforma Trabalhista), ampliando a forma de organização empresarial, permitindo maior liberdade de exercício de atividade econômica e ampliando a terceirização, entre outras medidas para a melhoria da economia e o incremento da iniciativa privada, mediante reestruturação da previdência, com aprovação da Reforma da Previdência (Emenda Constitucional n ${ }^{\circ}$ 103/2019), e desburocratização empresarial, a partir da edição da Lei da Liberdade Econômica (Lei nº 13.874/2019).

O fundamento liberal é imperativo em épocas de crise, como a gerada pela pandemia da covid-19, na qual o Estado deve regular as ações para a efetivação de uma liberdade econômica, com medidas para flexibilizar direitos trabalhistas, por exemplo, como as dispostas na Medida Provisória $n^{\circ}$ 927/2020 e na Lei $n^{\circ}$ 14.020/2020, para salvar empresas e empregos, pautando-se nos princípios que consagram os fundamentos da República brasileira, da dignidade da pessoa humana, dos valores sociais do trabalho e da livre iniciativa, mas também, garantir o desenvolvimento nacional, a marginalização e a redução das desigualdades sociais.

\section{A LIVRE INICIATIVA E A LIBERDADE ECONÔMICA: FUNDAMENTO, CONCEITO E LIMITES}

Na concepção hayekiana a liberdade econômica, base do Estado neoliberal, promotor da liberdade individual de empreender e mover a economia, é a mola mestra para o desenvolvimento social e a aquisição e manutenção da igualdade e da dignidade.

A livre iniciativa, fundamento da República Federativa do Brasil, ao lado do valor social do trabalho, consoante o inciso IV do art. $1^{\circ}$ da Constituição da República, combinado com o seu art. 170, norteiam a ordem econômica e social brasileira. 
A livre iniciativa endossa a todos o livre exercício de qualquer atividade econômica, independentemente de autorização de órgãos públicos, ressalvados alguns casos previstos em lei.

A ordem econômica deve ter por finalidade a garantia dos princípios da dignidade da pessoa humana e da justiça social, que, segundo Martins Filho (2012), são princípios importantes e relevantes de baixa densidade normativa, pois apenas são enunciados de fundamento da República, sem maiores detalhamentos.

Nos princípios de baixa densidade normativa, a doutrina encarrega-se de dar o conteúdo, enquanto o legislador não dá contorno necessário. Estes princípios passam a ser de alta relevância e abrangência, para a atividade econômica e o exercício profissional.

\subsection{Fundamento e conceito da livre iniciativa e da liberdade econômica}

Consoante a Constituição brasileira (Artigos $1^{\circ}, 3^{\circ}$ e 170), a ordem econômica é fundada na valorização do trabalho humano e na livre iniciativa; e tem por fim assegurar a todos existência digna, conforme os ditames da justiça social, observados os princípios da: soberania nacional; propriedade privada; função social da propriedade; livre concorrência; defesa do consumidor; defesa do meio ambiente; redução das desigualdades regionais e sociais; busca do pleno emprego; e do tratamento favorecido para as empresas de pequeno porte constituídas sob as leis brasileiras e que tenham sua sede e administração no País.

A livre iniciativa, fixada como fundamento da ordem econômica, no contexto do art. 170 da Constituição da República, deve ser desdobrada, de maneira que não seja prejudicial à pessoa humana e tenha como primado a justiça social. Para tanto, ensina Martins Filho (2006), sobre a ordem econômica e social, que a liberdade de iniciativa fica a encargo dos cidadãos e residentes, sendo missão do Estado apenas velar para que o abuso de poder econômico não ocorra; ou seja, o papel do Estado é atuar na economia como regulador, fiscalizador, entre outros, com vistas a salvaguardar o interesse coletivo.

Veja-se o pensamento de Ramos (1977, p. 209) sobre a livre iniciativa:

\footnotetext{
A liberdade de iniciativa econômica assenta sobre o pressuposto da concorrência. Somente esta, mesmo com imperfeições, tem o poder de evitar ou atenuar a dominação do mercado por um ou alguns produtores e consequentemente exploração dos consumidores, seja pela elevação desmedida dos preços, seja pela ausência de qualidade nos produtos. Não há outra forma, na economia de mercado,
} 
de conter esses abusos e de justificar, do ponto de vista do interesse coletivo, a liberdade empresarial.

A liberdade de iniciativa, consoante Silva (2004), somente é legitima quando exercida no interesse da justiça social; e será ilegítima, quando exercida com o objetivo de puro lucro e realização pessoal do empresário. A empresa deve desenvolver-se gozando das facilidades e limitações impostas pelo Estado, no contexto de justiça social.

Nesta esteira, a Lei da Liberdade Econômica estabelece princípios, direitos, diretrizes interpretativas e regulatórias da atividade econômica, os quais devem estar direcionados a garantir a liberdade de iniciativa. Esta lei flexibiliza certas formalidades em um modelo econômico neoliberal, reduzindo a burocracia para a abertura e o encerramento de empresas, instituindo a CTPS digital e trazendo modificações nas rotinas operacionais do departamento de pessoal das empresas, liberando algumas atividades econômicas de atos autorizativos para funcionamento, entre outras medidas de ordem prática e ambiental, como a permissão para manter documentos digitalizados, dispensando as empresas de guardar em meio físico, reduzindo gastos das empresas com rotinas arcaicas.

A figura central da livre iniciativa é o pleno exercício de atividades econômicas por todos, inclusive empresas, consagrado no regime constitucional brasileiro como fundamento da República e da ordem econômica, valorizando a integração entre o capital e o trabalho a partir dessa liberdade de iniciativa, com o intuito de desenvolvimento econômico, mediante a redução das desigualdades sociais e a busca do pleno emprego.

Para Bastos (1990, p. 16), a livre iniciativa e o livre exercício de atividade econômica consistem na manifestação dos direitos fundamentais de todos a se lançarem no mercado de produção de bens e serviços:

[...] o homem não pode realizar-se plenamente enquanto não lhe for dado o direito de projetar-se através da realização transpessoal. Vale dizer, por meio da organização de outros homens com vistas à realização de um objetivo. Aqui a liberdade de iniciativa tem conotação econômica. Equivale ao direito de todos têm de lançarem-se ao mercado de produção de bens e serviços por sua conta e risco. Aliás, os autores reconhecem que a liberdade de iniciar a atividade econômica implica a de gestão e a de empresa.

Para Eros Grau (2000) a livre iniciativa trata-se tanto de liberdade de empresa como de trabalho, abrangendo todas as formas de produção, individuais ou coletivas, esclarecendose que a livre iniciativa não consistirá na livre atuação da empresa privada no serviço público, 
mas sim que o Estado não deverá opor empecilhos à liberdade humana, coadunando ao pensamento hayekiano.

Em face da conjuntura política e econômica atual, com um Estado neoliberal, a intervenção do Estado reduzida, visa a estimular o empreendedorismo, o desenvolvimento econômico e a segurança para o particular gerar emprego e renda.

Neste diapasão, a empresa insere-se como o centro da aplicação do princípio da livre iniciativa, devendo receber tutela especial do Estado, no sentido de não ter o comprometimento do exercício de suas atividades econômicas, tendo em vista ser unidade produtora de bens e serviços para a sociedade e geradora de emprego e renda para os trabalhadores, como ilustra Martins Filho (2012).

Em face deste princípio, é importante que o Estado dispense aos que estão iniciando o empreendedorismo no país e gerando emprego e renda, como microempresas e empresas de pequeno porte, um tratamento jurídico diferenciado, visando a incentivá-las pela simplificação de suas obrigações administrativas, tributárias, previdenciárias e creditícias, ou pela eliminação ou redução destas por meio de lei, nos termos do art. 179 da Constituição da República, além de regras para garantir o livre mercado e a redução da burocracia para a abertura de empresas, prestigiando a autonomia da vontade das partes na celebração dos negócios.

O fundamento da livre iniciativa deve funcionar de forma equilibrada e sem abusos, pois este insere-se num contexto de conjunto de princípios constitucionais onde seus efeitos e resultados estão estabelecidos ante a finalidade de garantir a liberdade econômica e o progresso, garantindo o desenvolvimento nacional, erradicando a pobreza e reduzindo as desigualdades sociais e promover o bem-estar e a justiça social.

A ordem econômica é o conjunto de normas jurídicas que dizem respeito à economia, tem o perfil baseado nos princípios tradicionais do liberalismo econômico - a livre iniciativa, a livre concorrência e a propriedade privada, que ganham demarcação mais precisa com as normas infraconstitucionais que repreendem o abuso do poder econômico.

Como leciona Souza (2008, p. 3), nos seus comentários sobre a obra de Adam Smith,

[...] o liberalismo econômico pode ser compreendido como um sistema de expansão das liberdades na medida em que determina a livre iniciativa como princípio essencial para a sobrevivência do mercado; é a partir desta e da divisão do trabalho que se promove o crescimento econômico e bem-estar coletivo. 
As empresas privadas têm o poder de produção e circulação de bens e serviço, segundo o modelo neoliberal, objetivando o crescimento da economia, enquanto ao Estado, cabe assumir as funções de fiscalização, incentivo e regulação.

Os princípios da livre iniciativa, do livre exercício de qualquer atividade econômica, da livre concorrência e da propriedade privada são característicos e fundamentais para o funcionamento do capitalismo neoliberal, devendo permitir o pleno desenvolvimento das empresas, no plano da produção, circulação e distribuição das riquezas, assegurar a livre escolha das profissões e das atividades econômicas, bem como a utilização dos meios mais apropriados à consecução dos fins desejados com intervenção mínima do Estado.

Tavares (2006) delineia a livre concorrência como garantia de um sistema econômico eficiente e legítimo, como a abertura jurídica concedida aos particulares para competirem entre si, em segmento lícito, objetivando o êxito econômico pelas leis de mercado e a contribuição para o desenvolvimento nacional e a justiça social.

Nesta esteira, a Lei da Liberdade Econômica fora instituída em 2019, evidenciando as concepções hayekianas da livre iniciativa, da liberdade de atividade e da livre concorrência. Esta nova lei representa uma manifestação simbólica destinada a inspirar uma postura interpretativa menos intervencionista do Estado, tendo como amparo, os princípios constitucionais, que asseguram aos agentes econômicos liberdade de formular estratégias negociais indutoras de maior eficiência econômica e competitividade.

Isto posto, analisar-se-á no item seguinte a jurisprudência da Corte Superior brasileira acerca destes preceitos normativos à luz do pensamento de Hayek, objetivando responder a indagação se viabilizam a autonomia do particular para empreender em períodos de crise econômica e sanitária causada pela covid-19.

\subsection{Contornos de aplicação do pensamento liberal e da livre iniciativa para a preservação da empresa: análise jurisprudencial}

No pensamento neoliberal hayekiano, a liberdade (individual), que se inclui a liberdade econômica, é indispensável para o desenvolvimento da sociedade em todos os aspectos, inclusive para o seu sucesso, evolução e perpetuação (HAYEK, 2020b). 
Por meio dos ideais liberais e capitalistas, comprovadamente acertados para a civilização não virar escrava de um Estado socialista ineficaz, cada indivíduo ou organização carece de autonomia para empreender e competir espontaneamente (HAYEK, 2020a).

A livre concorrência, o livre mercado e a propriedade privada são salutares para o progresso econômico do País e a melhoria do ambiente de negócios.

Os princípios constitucionais da livre iniciativa e da liberdade econômica, no modelo econômico neoliberal, como analisado, dedicam-se a assegurar a todos a existência digna, garantir o desenvolvimento nacional, reduzir as desigualdades sociais e promover o bem-estar da sociedade.

Examinar-se-á neste item, a compatibilização dos princípios e valores liberais hayekianos e da livre iniciativa, a fim de permitir a manutenção da atividade empresarial, principalmente no tocante à saúde financeira das empresas atingidas diretamente pelos efeitos negativos da covid-19, por meio de recentes decisões do Supremo Tribunal Federal (STF).

Em 30 de agosto de 2018, o STF analisou a Arguição de Descumprimento de Preceito Fundamental (ADPF) 324/DF para reconhecer a licitude da terceirização de toda e qualquer atividade, meio ou fim, e que compete à contratante: verificar a idoneidade e a capacidade econômica da terceirizada; responder subsidiariamente pelo descumprimento das normas trabalhistas, bem como por obrigações previdenciárias, na forma do art. 31 da Lei n $^{\circ}$ 8.212/1991.

Ponderou o STF que a prática da terceirização já era válida no Direito brasileiro mesmo no período anterior à Reforma Trabalhista, independentemente dos setores em que adotada ou da natureza das atividades contratadas com terceira pessoa, reputando-se inconstitucional parte da Súmula 331 do TST, por violação, dentre outros princípios, da livre iniciativa.

Nesta decisão, o STF fixou a tese de que é lícita a terceirização ou qualquer outra forma de divisão do trabalho entre pessoas jurídicas distintas, independentemente do objeto social das empresas envolvidas, mantida a responsabilidade subsidiária da empresa contratante. Tendo como consectário, que a terceirização das atividades de uma empresa tem amparo nos princípios constitucionais da livre iniciativa e da livre concorrência (Artigos $1^{\circ} \mathrm{e}$ 170 da Constituição da República), que asseguram aos agentes econômicos a liberdade de formular estratégias negociais indutoras de maior eficiência econômica e competitividade. 
Ainda, fora destacado que os valores sociais do trabalho e da livre iniciativa constam em um mesmo inciso (Art. $1^{\circ}$, inciso IV, da Constituição), estando ligados em uma relação dialógica que impede seja rotulada determinada providência como maximizadora de apenas um desses princípios, não se podendo legitimar, binariamente, a intervenção restritiva em um sob o pretexto de homenagem ao outro, porquanto componentes de um mesmo núcleo comum e harmônico.

Por fim, a decisão do STF na ADPF 324 consagrou a liberdade, alinhando-se à concepção hayekiana; porém não só de iniciativa ou de concorrência empresarial, mas a jurídica, consistente na faculdade de fazer ou deixar de fazer o que quiser, exceto se houver vedação em lei, insculpida no art. $5^{\circ}$, inciso II, da Constituição da República, como princípio da reserva legal. Desta feita, a Súmula 331 do TST, construída jurisprudencialmente, não poderia determinar obrigação não fundada em lei, com intuito de frustrar a liberdade do empreendedor de organizar a sua atividade empresarial de forma lícita e eficiente, terceirizando, se desejar, quaisquer de suas atividades.

Coleciona-se, ainda, neste ensaio, duas decisões do STF no ano de 2020, fundamentadas nos preceitos hayekianos para fins de enfrentamento do estado de calamidade pública decorrente do coronavírus.

Em março e abril de 2020, o Governo Federal editou duas Medidas Provisórias (MP) de números 927 e 936, com medidas trabalhistas transitórias com o intuito de flexibilizar diversos institutos do Direito do Trabalho, como antecipação de férias e de feriados, determinação de tempo maior para a compensação de jornada e, as principais, como a possibilidade de negociar individualmente medidas de redução de jornada de trabalho e de salário e/ou de suspensão temporária do contrato de trabalho.

Estas normas suscitaram diversas discussões no STF quanto à sua constitucionalidade, culminando na Ação Direta de Inconstitucionalidade (ADI) 6363, quanto à Medida Provisória no 936/2020, e ADI 6344, que reúne as ADIs 6342, 6346, 6348, 6349, 6352 e 6354, quanto à Medida Provisória nº 927/2020.

Em resumo, ambas as medidas visavam garantir a subsistência digna do trabalhador com a manutenção do vínculo trabalhista, bem como fornecer alternativas para as empresas enfrentarem as dificuldades financeiras no período de pandemia da covid-19.

O STF nas ADIs supra mencionadas declarou válida as duas MPs em face das mesmas compatibilizarem os princípios constitucionais do valor social trabalho, perpetuando 
o vínculo trabalhista, e da livre iniciativa, permitindo a manutenção da atividade empresarial, principalmente no tocante à saúde financeira de micro, pequenas e médias empresas atingidas diretamente pelos efeitos negativos da crise sanitária e econômica gerada pelo coronavírus.

Primou-se pela convivência harmônica dos princípios que inspiram o Estado de Direito, que prestigia as liberdades.

Nessa jurisprudência de crise, como é denominada, prevaleceu a tese da livre iniciativa, a fim de permitir que as empresas permaneçam funcionando e os empregos garantidos, evitando-se uma legião de desempregados, que não terão condições de manter a sua dignidade. Neste sentido, os riscos para o capital humano são minimizados graças às políticas de preservação das relações entre empregado-empregador.

Insta salientar, que, o STF concebeu, neste período de calamidade pública, que o Governo conseguiu instituir medidas de exceção dentro do Estado de Direito, convergindo para a sobrevivência da empresa, do empregador e do empregado.

Finalmente, nos julgados houve ponderação dos princípios liberais e da livre iniciativa, em proveito do valor social do trabalho e da dignidade da pessoa humana, alicerces do Estado Democrático de Direito, imperando a premissa da preservação das empresas e da atividade econômica nacional, durante e após a pandemia da covid-19, congraçando com o pensamento de Hayek, pois sem atividade econômica não há empregos e nem renda para subsistência, não há arrecadação tributária, e, por fim, não há que se falar em promoção do bem-estar e de justiça social.

\section{CONSIDERAÇÕES FINAIS}

Ao Estado Democrático de Direito cabe garantir que os particulares tenham liberdade do exercício de sua atividade, com intervenção mínima e subsidiária, pois o crescimento econômico é essencial para a manutenção da economia, assegurando, contudo, o respeito aos direitos dos cidadãos, da valorização do trabalho e da dignidade da pessoa humana, a equidade e o progresso social.

A liberdade de iniciativa, conjugada a outros princípios neoliberais, norteia a ordem econômica e social, assegurando, pelo estabelecimento de condições institucionais, a liberdade econômica e ensejando, a quantos queiram produzir e trabalhar, o livre acesso ao 
mercado. Esta afluência não pode ser cercada por privilégios de qualquer natureza ou exigências legais e administrativas discriminatórias.

Neste ditame, é indubitável a aplicação dos princípios hayekianos a fim de assegurar, precipuamente, a liberdade e o pleno desenvolvimento da sociedade, visto que, sem estes não há empresas, empregos, renda e riqueza, bem como, outorgar a propriedade privada, no pensamento de Rand (2020), condição fundamental para os indivíduos exercerem plenamente o seu direito à vida, à liberdade econômica e à busca do bem-estar e da felicidade.

\section{REFERENCIAS}

BARROSO, Luís Roberto; CLÈVE, Clémerson Merlin. Doutrinas Essenciais. Direito constitucional. v. VI. São Paulo: Revista dos Tribunais, 2011.

BASTOS, Celso Ribeiro; MARTINS, Ives Gandra. Comentários à Constituição do Brasil. v. 7. São Paulo: Saraiva, 1990.

BRANCO, Adriano Murgel (Org.). Política energética e crise de desenvolvimento. São Paulo: Paz e Terra, 2002.

BRASIL. Supremo Tribunal Federal. Arguição de Descumprimento de Preceito Fundamental (ADPF) 324. Origem: DF - Distrito Federal. Relator: Min. Roberto Barroso. Direito do Trabalho. Arguição de descumprimento de preceito fundamental. Terceirização de atividadefim e de atividade-meio. Constitucionalidade. 6 setembro 2019. Disponível em: http://portal.stf.jus.br/processos/downloadPeca.asp?id=15341024987\&ext=.pdf. Acesso em: 01 dez. 2020.

BRASIL. Supremo Tribunal Federal. Ação Direta de Inconstitucionalidade (ADI) 6344. Origem: DF - Distrito Federal. Relator: Min. Marco Aurélio. Medida cautelar nas ADI 6342, 6344, 6346, 6348, 6352 E 6354. Direito constitucional e direito do trabalho. Medida Provisória 927/2020. Medidas trabalhistas para enfrentamento do estado de calamidade pública reconhecido pelo Decreto legislativo 6/2020. Normas direcionadas à manutenção de empregos e da atividade empresarial. Art. 29. Exclusão da contaminação por coronavírus como doença ocupacional. Responsabilidade objetiva do empregador. Art. 31. Suspensão da atuação completa dos auditores fiscais do trabalho. Ausência de razoabilidade. Suspensão da eficácia dos arts. 29 e 31 da MP 927/2020. Concessão parcial da medida liminar. 12 novembro 2020.2 Disponível em: http://portal.stf.jus.br/processos/downloadPeca.asp?id=15344947226\&ext=.pdf. Acesso em: 01 dez. 2020.

BRASIL. Supremo Tribunal Federal. Ação Direta de Inconstitucionalidade (ADI) 6363. Origem: DF - Distrito Federal. Relator: Min. Ricardo Lewandowski. Direito do trabalho. Acordo e convenção coletivos do trabalho. Questões de alta complexidade, grande impacto e 
repercussão. Covid-19. 24 novembro 2020. Disponível em: http://portal.stf.jus.br/processos/downloadPeca.asp?id=15345059901\&ext=.pdf. Acesso em: 01 dez. 2020.

CASTRO, Carlos Alberto Farracha. Preservação de empresa no Código Civil. Curitiba: Juruá, 2007.

COELHO, Fábio Ulhoa. Curso de Direito Comercial. V. 1: direito de empresa. 12. ed. São Paulo: Saraiva, 2008.

CUNHA, Belinda Pereira. TEIXEIRA, Osvaldo de Freitas. A liberdade econômica como pressuposto para o desenvolvimento nacional. Revista Direito e Desenvolvimento. a. 2, n. 4. João Pessoa, jul.-dez., 2011.

DARDOT, Pierre. LAVAL, Christian. A nova razão do mundo: ensaio sobre a sociedade neoliberal. trad. Mariana Echalar. São Paulo: Boitempo, 2016.

DI PIETRO, Maria Sylvia. Parcerias na administração pública. 11. ed. São Paulo: Forense, 2017.

GANEM, Angela. Hayek: da teoria do mercado como ordem espontânea ao mercado como fim da história. Revista Política \& Sociedade. vol. 11. n. 22. Florianópolis, nov. 2012.

GRAU, Eros. A ordem econômica na Constituição de 1988. 5. ed. São Paulo: Malheiros, 2000 .

HAYEK, Friedrich August von. Los fundamentos de la libertad. 7. ed. Madrid: Unión, 2006.

HAYEK, Friedrich August von. Desestatização do dinheiro. São Paulo: LVM, 2011.

HAYEK, Friedrich August von. O caminho da servidão. Trad. Anna Maria Capovilla. 7. ed. São Paulo: LVM, 2020a.

HAYEK, Friedrich August von. $O$ argumento completo em defesa da liberdade. Mises Brasil. São Paulo, 16 mai. 2020b. Disponível em: https://www.mises.org.br/article/2225/oargumento-completo-em-defesa-da-liberdade. Acesso em: $01 \mathrm{dez} .2020$.

LEME, Alessandro André. Neoliberalismo, globalização e reformas do estado: reflexões acerca da temática. Santa Cruz do Sul, n. 32, p. 114-138, jun. 2010. Disponível em: http://pepsic.bvsalud.org/scielo.php?script=sci_arttext\&pid=S0104-

65782010000100008\&lng=pt\&nrm=iso. Acesso: em 01 dez. 2020.

MARTINS, Ives Gandra da Silva. O estado de direito e o direito do estado. São Paulo: Lex Editora, 2006. 
MARTINS FILHO, Ives Gandra da Silva Martins. Os pilares do direito do trabalho: princípios e sua densidade normativa. Revista de Direito do Trabalho. n. 49, jul.-ago. São Paulo: Magister, 2012.

MELlo, Celso Antônio Bandeira. Curso de direito administrativo. 34. ${ }^{a}$ ed. São Paulo: Malheiros, 2019.

MISES, Ludwig von. O contexto histórico da escola austríaca de economia. São Paulo: LVM, 2017.

ONOFRE, Gabriel. Friedrich Hayek e os liberais brasileiros na transição democrática. Revista crítica histórica. Ano V, n. 10, dez. 2014. Disponível em: file:///C:/Users/Windows/Downloads/2956-10783-1-PB.pdf. Acesso em: 01 dez. 2020.

PAZ, Anderson Barbosa. O estado de direito para F. A. Hayek. João Pessoa, 2019. Disponível em: https://core.ac.uk/download/pdf/297212962.pdf. Acesso em: 01 dez. 2020.

PEDROSA, Ronaldo Leite. Direito em história. 4. ed. Nova Friburgo: Imagem Virtual, 2002.

RAMOS, José Nabatino. Sistema brasileiro de direito econômico. São Paulo: Resenha Tributária. IBDT, 1977.

RAND, Ayn. A virtude do egoísmo. trad. Matheus Pacini. São Paulo: LVM Editora, 2020.

SAUER, Ildo Luís. Energia elétrica no Brasil contemporâneo: a reestruturação do setor, questões e alternativas. São Paulo: Paz e Terra, 2002.

SEVERO, Valdete Souto. A dimensão plural do trabalho humano e a inconstitucionalidade do banco de horas. Revista da Justiça do Trabalho, n. 274, out. 2006, Porto Alegre: HS, 2006.

SILVA, José Afonso da. Curso de Direito Constitucional Positivo. 23. ed. São Paulo: Malheiros, 2004.

SMITH, Adam. Riqueza das nações. V. 1 e 2. Lisboa: Fundação Calouste Gulbenkian, 1981 e 1983.

SOUSA, Mônica Teresa Costa. Adam Smith e o liberalismo econômico: uma defesa. São Luís, 2008.

SZTAIN, Rachel. Teoria jurídica da empresa: atividade empresária e mercados. São Paulo: Atlas, 2004.

TAVARES, André Ramos. Direito constitucional econômico. São Paulo: Método, 2006. 